\section{Stability Analysis of Reinforced Slopes}

\author{
J. Greenwood, BSc., MEng. MICE., MIHT
}

THE paper by Terry Ingold ("Highways and Transportation', March 1996) tackles important aspects of geotextile reinforced embankments over soft ground and provides some helpful design guidelines for the complex problems of soil and reinforcement interaction.

On the question of stability analysis the application of the 'Bishop' method is not straightforward because the factor of safety appears on both sides of the equation. The validity of applying a constant factor of safety to each slice of the analysis has been questioned by Chugh (1985) and the inaccuracies of the Bishop equation for deep slip surfaces (high negative values of $\propto$ | have been reported previously (Skempton and Hut. chinson 1969. Turnbull and Hvorslev 1967.

These problems are overcome if the Simple equation (1) is applied.

This equation based on conventional shoar strength theory (Greenwood 1983, Turnbull and Hvorsiev 1967) assumes resultant inter-slice forces are paraliel to the slip surface. It gives sensible, consistent factors of safety for shallow and deep, circular or non-circular slip surfaces and with high or low water pressures.

The simple equation is readily adapted for reinforcement forces, i.e. equ (2)

The terminology is as used by Terry Ingoid except that $T$ is the availabie reinforcement force operating on the slice considered. This is illustrated in Figure 1. Ru or u may be used for water

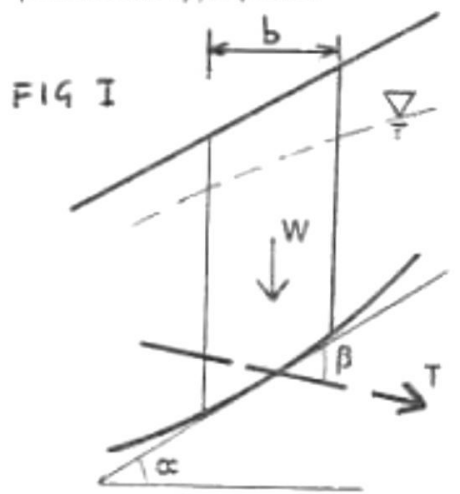

W total weight of soil slice.

$c$ ' $\phi$ ' effective strength parameters at the slip surface.

u pore water pressure at slip surface.

Ru pore water pressure ratio $\left(R u=\frac{u b}{W}\right.$ pressure as appropriate.

$$
\begin{aligned}
& F=\frac{1}{\sum W \sin \alpha} \sum[c b \sec \alpha+(W-a b) \cos \alpha \tan \theta] \\
& F=\frac{1}{\sum W \sin \alpha} \sum\left[c b \sec \alpha+[(W-u b) \cos \alpha+T \sin \beta] \tan \theta^{\prime}+T \cos \beta\right] \quad \text { (2) }
\end{aligned}
$$

\title{
THEAUTHOR
}

JOHN GREENWOOD is the Regional Geotechnical Engineer for the Department of Transport's Eastern Regional Office, Bedford. After graduating from Kings Col. lege, London in 1969 he completed a Masters Degree at McMaster University. Ontario and spent a further two yoars in Canada.

$\mathrm{He}$ returned to the UK in 1972 and worked in the geotechnical sections of Sir Wiliam Halcrow and Partners and Mott Hay and Anderson. He joined the Depart. ment in 1976 and has been a member of this institution since 1983.

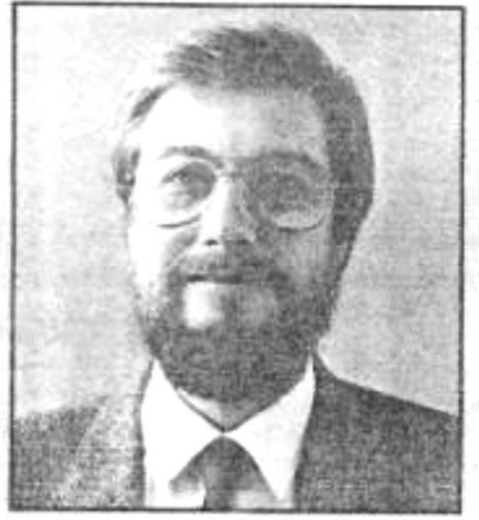

available teinforcement (o: arichor) force operating on base of slice considered. (allowing for strain com patability, creep, weathering effects, anchorage lengths etcl.

Equation (2) includes an enhanced normal stress component, $T \sin B$, in addition to the tensile restoring component TeaB. The extent to which both the tensile and normal compenents will be mobilised depends on the strain characteristics of the roinforcement. Stiffer geomesh materials may rapidly develop both tensile and normal components but geotextiles requiring greater strain to develop their strength may not provide sufficient resistance betore ex. cessive straining of the soif occurs. For reinforcement placed without pre. tensioning it is suggested that the normal contribution is ignored, i.e. conservatively assume $T \operatorname{Sin} B=0$, unless experimental evidence is available to demonstrate that it can be relied on.

When equation (2) is applied to pre. tengioned anchor type reinforcement both tensile and normal components may be included. Anchor reinforcement is predominantly at right angies to the slope and the initial benefit will be main. ly in terms of increased normal stress on the potential shear surface (T sin B). OnIy if failure commences will the anchor cable distort and provide a tensile restraining force, $T \cos B$.

The charts given by Terry Ingold are of limited practical value because they only cover particular cases and do not allow for water pressure or variable stope geometry. By applying equation (2) the designer can carry out his own 'simplified' analysis, as illustrated in the example, and begin to develop an understanding of the problem and its particular features.

Figure 2 gives an exarmple of a 'com puter assisted' hand calculation for the stability of a clay embankment with three layers of geomesh reinforcerment at its base. The input data is obtained by measurement from the diagram. The computer program Iwritten by Mertin Wheeler) calculates the factors of safety of the unreinforced slope by five dif. ferent methods. Input data may be edited for parametric studies, In this example the 'Bishop' factor of safety is shown to be somewhat optimistic in relation to the other methods. The reinforced factors of safery are calculated by the simple equation (2), firstiy with the tensile contribution only, assuming $T$ sin $B=0$, and secondly including both the tensile and normal contributions. The designer mav then decide whether the additional benefits of the normal con. tribution can be relied on.

Siope stability is itself a complex subject and the addition of reinforcement to the soil requires careful consideration. For example the embedment lengthe necessary to ensure that the required 
SLOPE STABILITY

ANALYSIS PROGRAM

SLIP ERO (T) BEDFORD

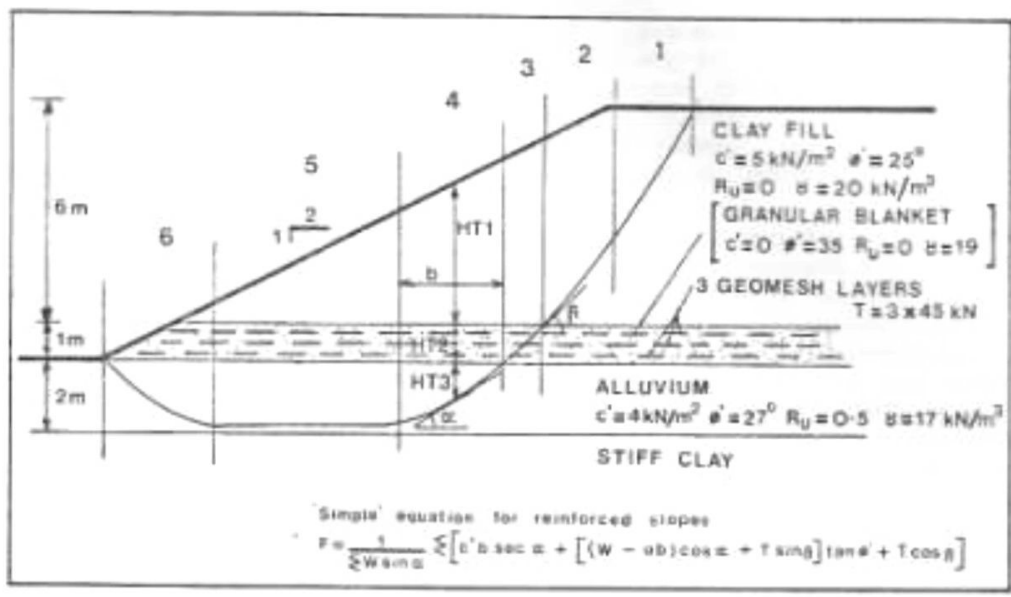

INPUT DATA FROM DIAGRAM

RU INITIALLY INPUT HW CALCULATED

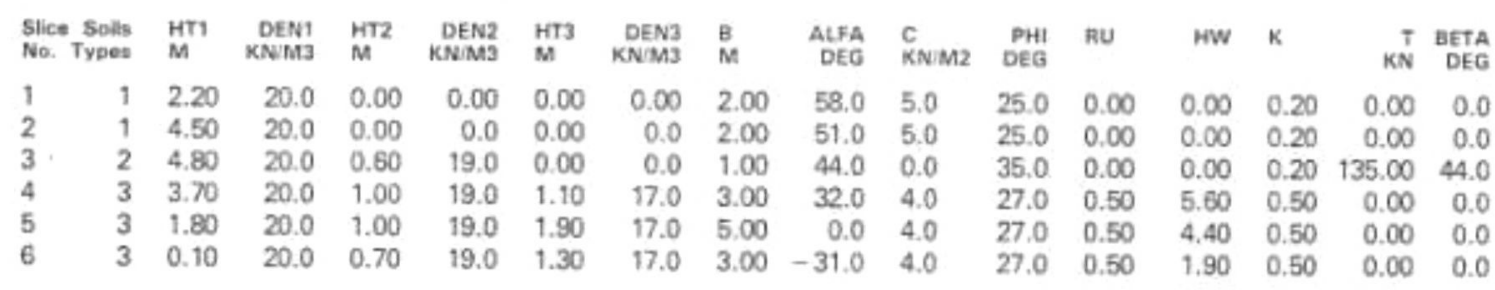

OUTPUT DATA

FORCES IIN KILO NEWTONS) IN EACH SLICE

SIMPLE WOOD SWEDISH BISHOP JANBU RESISTANCE FROM

SLICE WEIGHT DISTUAB. COHESIVE TOTAL TOTAL TOTAL TOTAL TOTAL TENSILE NORMAL

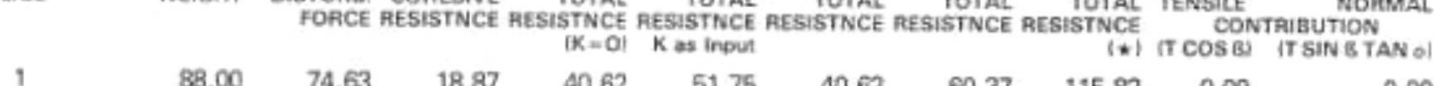

$\begin{array}{lrrrrrrrrrr}1 & 88.00 & 74.63 & 18.87 & 40.62 & 51.75 & 40.62 & 60.37 & 115.82 & 0.00 & 0.00 \\ 2 & 180.00 & 139.89 & 15.89 & 68.71 & 84.82 & 68.71 & 102.28 & 166.06 & 0.00 & 0.00 \\ 3 & 107.40 & 74.61 & 0.00 & 54.10 & 64.19 & 54.10 & 67.91 & 96.17 & 97.11 & 65.66 \\ 4 & 335.10 & 177.58 & 14.15 & 86.55 & 100.68 & 58.28 & 91.56 & 111.39 & 0.00 & 0.00 \\ 5 & 436.50 & 0.00 & 20.00 & 131.20 & 131.20 & 131.20 & 131.20 & 137.76 & 0.00 & 0.00 \\ 6 & 112.20 & -57.79 & 14.00 & 38.50 & 42.92 & 29.66 & 62.65 & 78.98 & 0.00 & 0.00 \\ \text { TOTAL } & 1259.20 & 408.91 & 82.91 & 419.57 & 475.68 & 382.56 & 515.97 & 706.19 & 97.11 & 65.66\end{array}$

( ) Janbu resistance not directly comparibie with other solutions

FACTORS OF SAFETY (NO REINFORCEMENT)

Simpie $\{K=0\}$

Greenwood (Kas input)

Bishop

Janbu $\{$ fo $=1.05$ )

\section{FACTORS OF SAFETY ISIMPLE SOLUTION]}

No reintorcement

Reinforced (tensile \& normal contribution)

- FIGURE 2. Example analysis of a reinforced siope.

reinforcement force is available need to be checked together with the effect that the reinforcement has on shifting the location of the most critical slip surface. The simple analysis described in this note gives a basic guide to potential benefits of reinforcernent and should give the designer confidence to tacikie the more camplex probiems of interac. tion between soil and reinforcement. ACKNOWLEDGEMENT

THIS note is published by kind permission of the Desuty Secretary, Highways and Traffic, Department of Transport Views expressed are those of the author and should not be attributed to the Department of Transport.

\section{REFERENCES}

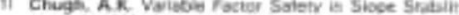

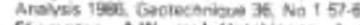

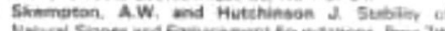

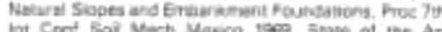

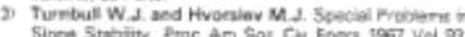

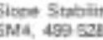

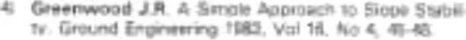

